\title{
Actividad in vitro de bacterias endófitas promotoras de crecimiento asociadas con pasto colosoana en el municipio de Corozal, Sucre
}

\author{
Activity in vitro of bacteria endophytes promoters of growth associated with \\ colosoana pasture in the municipality of Corozal, Sucre
}

DONCEL M, ARTURO ${ }^{1 *}$, Zoot, CHAMORRO A, LEONARDO² M.Sc, PÉREZ C, ALEXANDER² Ph.D.

1 Universidad de Sucre, Facultad de Educación y Ciencias,
${ }^{2}$ Universidad de Sucre, Facultad de Ciencias Agropecuarias.
Grupo Bioprospección Agropecuaria, Sincelejo, Sucre.

\section{Keywords:}

Bacteria;

pasture;

fixing biological of nitrogen; solubilization of phosphate.

\begin{abstract}
The objective of study was evaluated in vitro binding activity of nitrogen and phosphate bacteria endophytic solubilizated isolated from different tissues of colosoana grass in the districts of the municipality of Corozal, Sucre Department. Collected sample of roots stems and leaves of colosoana pasture from different farms. Of each tissue previously disinfected is made isolation in the middle of cultivation of bacteria endophytic, to which is les determined it density population of bacteria endophytic by means of count in UFC / $\mathrm{g}$ of tissue and is carried out separation of morphs by shape, color, size and appearance in media of crops. Each isolated morphotype was evaluated in vitro binding activity of nitrogen and phosphate solubilizing specific crops media. Are observed differences significant for density population of bacteria with respect to tissue, with higher values in root $\left(1 \times 10^{11} \mathrm{~g} /\right.$ root $)$, followed of the stem $\left(1.82 \times 10^{10} \mathrm{~g} / \mathrm{stem}\right)$ and with leaf density sheets $\left(1.15 \times 10^{10} \mathrm{~g} / \mathrm{leaf}\right)$. The results of the identification kit API20E confirmed the presence of bacteria endophytes Pseudomonas aeruginosa and Stenotrophomonas maltophilia with ability to fix nitrogen and solubilize phosphates.
\end{abstract}

Palabras Clave:

Bacteria;

pasto;

fijación biológica de nitrógeno; solubilización de fosfato.
INFORMACIÓN

Recibido: 20-08-2016;

Aceptado: 19-11-2016.

Correspondencia autor:

arturo.doncel@unisucre.edu.co

\section{Resumen}

El presente estudio tuvo como objetivo evaluar in vitro la actividad fijadora de nitrógeno y solubilizadora de fosfato de bacterias endófitas aisladas de diferentes de tejidos de pasto colosoana en los corregimientos del municipio de Corozal, departamento de Sucre. Se colectaron muestra de raíz, tallos y hojas de pasto colosoana. De cada tejido previamente desinfectado se realizó aislamiento en medio de cultivo para bacterias endófitas, a las cuales se les determinó la densidad poblacional por medio de conteo en UFC/ $\mathrm{g}$ de tejido y se separación de morfotipos por forma, color, tamaño y apariencia en medios de cultivos. A Cada morfotipo aislado se le evaluó in vitro su actividad fijadora de nitrógeno y solubilizadora de fosfato en medios de cultivos específicos. Se observaron diferencias significativas para densidad poblacional de bacterias con respecto a tejido, con mayores valores en raíz $\left(1 \times 10^{11} \mathrm{~g} /\right.$ raíz), seguida del tallo $\left(1.82 \times 10^{10} \mathrm{~g} / \mathrm{tallo}\right)$ y menor densidad en hojas $\left(1.15 \times 10^{10} \mathrm{~g} / \mathrm{hoja}\right)$. Los resultados de la identificación con kit API20E confirmaron la presencia de las bacterias endófitas Pseudomona aeuroginosa y Stenotrophomonas maltophilia con capacidad de fijar nitrógeno y solubilizar fosfatos. 


\section{Introducción}

El pasto colosoana, Bothriochloa pertusa (L.) A. Camus, es una planta originaria de Asia y África y perteneciente a la tribu Andropogonae, subfamilia Panicoidae, familia Gramineae (TROPICAL FORAGES, 2013). A nivel global se han identificado diferentes especies de Bothriochloa, encontrándose alrededor de 35 y sus cultivares. Se considera que el Sur de Asia y Sudeste Asiático (India, Pakistán, Sri Lanka, Tailandia, Indonesia y Malasia) son el centro de origen de B. pertusa (LASCANO Y ARGEL, 2011). En América latina y principalmente en ciertas regiones de Colombia existen extensas áreas ganaderas en las que este pasto, conocido como Colosoana, se ha naturalizado. Esta planta se considera en la actualidad como uno de los principales recursos forrajeros presente en los sistemas de producción bovina de la región Caribe de Colombia (VERA, 2004), y aunque su amplia distribución se debe más a la forma como ha colonizado por invasión extensas áreas de la zona, debido a sus cualidades fisiológicas, no deja de ser importante a la hora de cuantificar el aporte alimenticio que hace para mantener la producción vacuna en la Región.

El pasto Colosoana (Bothriochloa pertusa) ha colonizado la mayoría de praderas Colombianas desplazando diversas especies de gramíneas mejoradas, considerándola por algunos ganaderos como una maleza. Lamentablemente, la escasez de literatura sobre trabajos de investigación en lo que refiere a propiedades de la planta y su comportamiento en diferentes suelos y su respuesta al uso de fertilizantes, no permite el aprovechamiento de las propiedades de adaptación y producción que sería más útiles para los productores (PORTELA et al., 2011).

En los sistemas ganaderos de la región Caribe colombiana, la alimentación de los bovinos depende casi exclusivamente del forraje producido en las praderas. Durante los largos períodos de sequía que cada año se presentan en la zona, la producción y calidad del forraje se reducen en forma dramática, constituyéndose en la principal causa de los bajos índices zootécnicos de la ganadería regional. Los sistemas ganaderos en la región Caribe presentan actualmente baja eficiencia biológica y económica, lo cual obedece en parte a la baja calidad nutricional y disponibilidad de las gramíneas nativas o introducidas principalmente durante la prolongada estación seca (CAJAS et al., 2003).

Los microorganismos endófitos son definidos como aquellos presentes en la superficie de tejidos vegetales desinfectada o en su interior, que no producen efectos nocivos para la planta (HARDOIM et al., 2008). Estos se pueden encontrar en espacios intracelulares y en tejidos vasculares de tallos y raíces. Esta asociación endófito-planta, forma un sistema en el cual el microorganismos comunica información de la planta hospedera a ellos y viceversa (PÉREZ et al., 2010). Las investigaciones revelan que las bacterias endófitas tienen la capacidad de promover el crecimiento y aportar nutrientes para el desarrollo de la planta, fijar nitrógeno(DUTTA y GACHHUI, 2006) y solubilizar fosfato (DAWWAM et al., 2013), aumentar la resistencia de la planta actuando como biocontroladores (Yang et al., 2013), promover la fitoremediación (AFZAL et al., 2014) y producir metabolitos secundarios y otros productos naturales empleados en la medicina como antibióticos, antivirales, antioxidantes, entre otros (SHWETA et al., 2013) .

Las bacterias están asociadas a las plantas como patógenas, epífitas y endófitas; muchas de estas forman asociaciones íntimas con las plantas y conforman diversos grupos filogenéticamente representados por especies pertenecientes a los principales taxones. Las bacterias asociadas a las plantas típicamente intercambian señales moleculares con su hospedero y poseen diversos mecanismos para adaptación y colonización (PÉREZ et al., 2010). Aspectos importantes de la diversidad de bacterias en el ecosistema incluyen los diferentes procesos que estas realizan, la complejidad de la interacción y el número de niveles tróficos que los componen. Recientemente ha surgido interés en temas relacionados con la composición, estructura y función de las comunidades de bacterias en diferentes ambientes (BENEDUZI et al., 2013).

La densidad poblacional de bacterias endófitas es altamente variable, depende de la especie de bacteria y del genotipo de la planta hospedera, además del estado de desarrollo de la planta, la densidad del inóculo y las condiciones ambiental 
(WARD, 2006). Estudios moleculares reciente sobre la diversidad de bacterias endófitas han revelado una alta riqueza de especies, que promueven el crecimiento de las plantas, suprimen fitopatógenos, ayudan a remover contaminantes, solubilizan fosfato y contribuyen a la asimilación biológica de nitrógeno (ROSENBLUETH y MARTÍNEZ, 2006). Las bacterias endófitas son consideradas como modelo de estudio de expresión génica en su nicho natural o hábitat dentro de las plantas (MARON et al., 2007). Sin embargo, cuestiones básicas sobre la diversidad microbiana existente en plantas comerciales, así como la estructura de esas comunidades y la funcionalidad en diferentes especies vegetales localizadas en diversos ambientes geográficamente definidos, deben ser objeto de investigaciones modernas en lo referente a la presencia de bacterias endófitas, diversidad y relación con la productividad y sostenibilidad en agroecosistemas específicos.

La fijación biológica del nitrógeno atmosférico ha sido considerada como el segundo proceso más importante que se lleva a cabo en la naturaleza, después de la fotosíntesis (SYLVIA et al., 2005). En la ausencia de fertilizantes nitrogenados o residuos de animales la dinámica de los agroecosistemas depende enteramente de un grupo de microorganismos que tienen la habilidad para reducir el nitrógeno atmosférico a nitrógeno orgánico. Este nitrógeno orgánico es convertido a diferentes formas químicas, las cuales pueden ser utilizadas por las plantas y por los mismos microorganismos para suplir total o parcialmente sus requerimientos de síntesis de proteínas y otros compuestos orgánicos. Este proceso de conversión de nitrógeno atmosférico se debe a que estos microorganismos tiene la capacidad de sintetizar un complejo enzimático denominado nitrogenasa ( HU y RIBBE, 2013).

De otra parte, otro elemento es el fósforo que menudo aparece como un nutriente limitante en los suelos agrícolas y no es posible capturarlo biológicamente desde el aire, como ocurre con el nitrógeno. Su ciclo natural involucra largos períodos, lo que en términos de manejo agrícola equivale a decir que no se puede depender del ciclo del fósforo, sino de la posibilidad de generar determinados flujos y sub-ciclos de él al interior de los sistemas suelo-agua-organismos vivos. Sin embargo los sub-ciclos se ven dificultados porque los equilibrios de reacción del fósforo tienden a mantener la mayor parte de él en condiciones no disponibles para las plantas o microorganismos (HERNÁNDEZ y CHAILLOUX, 2001). De allí la importancia de algunos microorganismos, los cuales a través de diferentes mecanismos logran poner éste fósforo a disposición de las plantas. Los principales mecanismos son por medio de asociaciones micorrízica, que provocan una mayor extensión del sistema radicular y por estimulación de procesos metabólicos, especialmente excreción de ion hidrógeno, liberación de ácidos orgánicos (cítrico, oxálico, glucónico, láctico, málico etc), producción de sideróforos y la producción de la enzima fosfatasa, que es útil para la hidrólisis del fósforo orgánico del suelo.

En particular, los ácidos orgánicos y protones asociados son efectivos en la solubilización de formas precipitadas del fósforo del suelo (hierro y aluminio en suelos ácidos y calcio en suelos alcalinos), en la quelación de metales que pueden estar asociados a formas complejas del fósforo o pueden facilitar la liberación de fósforo absorbido a través de reacciones de intercambio (ALIKHANI et al., 2007). Se han identificado diferentes especies que solubilizan fosfatos, dentro de ellas se encuentras las pertenecientes a los géneros Pseudomonas, Erwinia, Enterobacter, RahmellaSerratia, Synechococcus, Agrobacterium, Burkholderia, Aerobacter, entre otras, las cuales no solo asimilan dicho elemento, sino que lo solubilizan en grandes cantidades del mismo (RODRIGUEZ et al., 2006).

Con base en todo lo anterior, se planteó la realización del presente estudio cuyo objetivo cuyo objetivo de evaluar in vitro la actividad de bacterias endófitas promotoras de crecimiento aisladas de diferentes tejidos de pasto colosoana en el municipio de Corozal, departamento de Sucre.

\section{Materiales y métodos}

Identificación de fincas con pasto colosoana en los corregimientos del municipio de Corozal. El trabajo se llevó a cabo en dos etapas: en campo y laboratorio. En la primera etapa se procedió, con base a información suministrada por ganaderos de la región, a seleccionar las áreas establecidas únicamente con pasto colosoana para la toma 
de muestras (raíz, tallo y hojas). Las muestras depositadas en bolsas estériles, rotuladas y conservadas se trasladaron al laboratorio de Investigaciones microbiológicas de la Universidad de Sucre para su respectivo análisis.

Aislamiento de endófitas. La muestras de raíz, tallo y hojas, recolectada en cada finca ganadera fueron sometida a proceso de desinfección superficial utilizando metodología propuesta por PÉREZ et al., (2010). El proceso consistió en: dos lavados de la raíz en agua destilada estéril, seguida de agitación por 15 min en solución tampón de fosfato de potasio $0.05 \mathrm{~mol} \cdot \mathrm{L}^{-1}, \mathrm{pH}$ 7.0; inmersión por 1 min en alcohol $70 \%$; agitación por 5 min en solución de hipoclorito de sodio $5 \%$ y Tween $80 \%$; nuevamente se realizó inmersión por 1 min en alcohol $70 \%$ seguida de agitación por 15 min en solución tampón fosfato de potasio $0.05 \mathrm{~mol}^{-1}, \mathrm{pH} 7.0 \mathrm{y}$, finalmente, se lava cuatro veces en agua destilada esterilizada. El proceso se repitió dos veces.

Para la confirmación del proceso de esterilización de la superficie de los tejidos de raíz, tallo y hojas, la alícuota del último lavado se esparció en placa conteniendo medio de cultivo agar R2A e incubada a $28^{\circ} \mathrm{C}$ por 72 horas. Seguidamente, cada tejido esterilizado por separado se transfirió a tubos conteniendo caldo de R2A y se incubaron a $28^{\circ} \mathrm{C}$ por 72 horas, para la confirmación de la inexistencia de microorganismos epifíticos en la superficie de los tejidos.

Densidad poblacional. Para cuantificar el total de bacterias endófitas, se tomó un g de cada tejido desinfectado, el cual se trituró en nitrógeno líquido. El macerado homogéneo obtenido se transfirió a un tubo con $9 \mathrm{~mL}$ de agua peptona y se agitó vigorosamente. A partir de esta solución se prepararon diluciones seriadas $\left(10^{-1}\right.$ a $\left.10^{-8}\right)$ por triplicado, las cuales se inocularon mediante la técnica de siembra en superficie en el medio agar R2A e incubadas a $28^{\circ} \mathrm{C}$ por 72 horas. La densidad poblacional de bacterias endófitas (UFC/g de raíces-1) se estimaron por conteo directo de colonias en placas. Durante el conteo se observaron y se seleccionaron las colonias que se distinguían en cuanto a forma, aspecto de la superficie, color y tamaño. Los morfotipos seleccionados se purificaron y se conservaron en agar R2A para su posterior análisis bioquímico.
Fijación biológica de nitrógeno. Para esta técnica se realizó una siembra directa de la bacteria en superficie. Se utilizó un medio de cultivo selectivo carente de nitrógeno (Medio ASHBY), porque utiliza una fuente combinada de carbono que permite recuperar mayor cantidad de microorganismos y donde solo crecerán aquellas que poseen el sistema enzimático que les permite reducir el nitrógeno atmosférico y utilizarlo en su metabolismo.

Solubilización de fosfato. Se realizó una siembra directa de la bacteria en superficie. Para el aislamiento de estos microorganismos se utilizó el medio de cultivo sólido según Sundara, Rao y Sinha (SRS). Este medio de cultivo contiene sales de fosfato de calcio y púrpura de bromocresol como indicador de $\mathrm{pH}$. Aproximadamente a los 6 días de siembra se seleccionaron las colonias bacterianas que crecían acidificando el medio (viraje de color rojo a amarillo) y formando un halo transparente, indicando actividad solubilizadora de fosfato.

Identificación de bacterias endófitas. Las bacterias con actividad positiva para fijación biológica de nitrógeno y solubilización de fosfatos, se identificaron por kit de pruebas bioquímicas API 20E. La batería de pruebas API20E es un sistema de identificación rápida para bacterias de la familia Enterobacteriaceae y otras bacterias Gram-negativas, consta de 21 tests bioquímicos estandarizados y miniaturizados, y una base de datos. Este sistema presenta las ventajas de ser rápido, eficaz y de permitir realizar numerosas pruebas a la vez

\section{Resultados y Discusión.}

Aislamiento y densidad de bacterias endófitas. Se obtuvieron un total de 51 morfotipos de bacterias endófitas, las cuales fueron aisladas de diferentes tejidos de pasto colosoana. La densidad poblacional de estas bacterias varió en un rango de $2.45 \times 10^{8} \pm 4.48 \times 10^{10}$ de tejido. Estudios realizados por Perez et al. (2014) sobre densidad poblacional de bacterias endófitas asociadas a la especie de pasto colosoana en tres localidades del departamento de Sucre, encontraron densidades promedias $3.24 \times 10^{9} \pm$ $2.2 \times 10^{10} \mathrm{UFC} / g$ por $g$ de tejido para esta especie de pasto. Los resultados del análisis multifactorial 
entre densidad poblacional en función a zona, finca y tejidos muestran diferencias altamente significativas para cada variable (Tabla 1)

Tabla 1. Análisis multifactorial de densidad poblacional (UFC) de bacterias endófitas en función a zona, finca y tejidos de pasto colosoana pertenecientes a fincas ganaderas de los corregimientos del municipio de Corozal, departamento de Sucre, Colombia. 2016.

\begin{tabular}{cccccc}
\hline $\begin{array}{c}\text { Fuente de } \\
\text { variación }\end{array}$ & $\begin{array}{c}\text { Suma de } \\
\text { cuadrados }\end{array}$ & gl & $\begin{array}{c}\text { Cuadrado } \\
\text { medios }\end{array}$ & Razón F & Valor-P* \\
\hline Fincas & $4.65 \times 1020$ & 4 & $1.10 \times 1020$ & 3.24 & 0.0063 \\
Tejidos & $2.58 \times 1020$ & 2 & $1.54 \times 1020$ & 4.28 & 0.0132 \\
Zonas & $3.18 \times 1020$ & 2 & $1.34 \times 1020$ & 3.77 & 0.0076 \\
Residuos & $4.12 \times 1021$ & 120 & $3.31 \times 1020$ & & \\
\hline Total & $4.60 \times 1021$ & 134 & & & \\
\hline
\end{tabular}

${ }^{*}$ Diferencia altamente significativa con un $95.0 \%$ de nivel de confianza

Los resultados de la prueba múltiple de rangos para densidad poblacional de bacterias endófitas por corregimiento (Figura 1), señalan que el corregimiento de Las Peñas presentó mayores densidades poblacionales $\left(4.48 \times 10^{10} \mathrm{UFC} / \mathrm{g}\right.$ de tejido), seguida del corregimiento del Mamón (3.31 $\times 10^{10} \mathrm{UFC} / \mathrm{g}$ de tejido), Canta Gallo $\left(2.8 \times 10^{10}\right.$ UFC/g de tejido), Chapinero $\left(2.45 \times 10^{10} \mathrm{UFC} / \mathrm{g}\right.$ de tejido), con respecto al corregimiento de Hato nuevo que obtuvo la menor densidad poblacional de bactérias endófitas $3.18 \times 10^{8} \mathrm{UFC} / \mathrm{g}$ de tejido respectivamente.

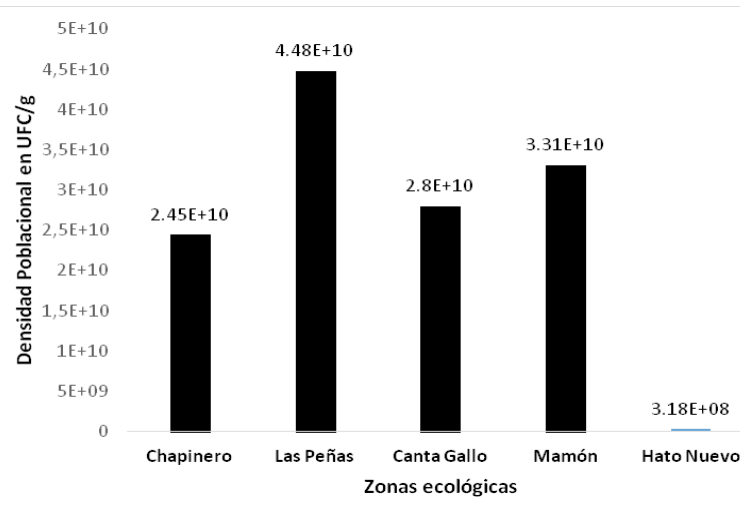

Figura 1. Resultados prueba múltiple de rango para densidad poblacional de bacterias endófitas en función a corregimiento municipio de Corozal-Sucre- Colombia. Año 2016.

La prueba múltiple de rangos para densidad poblacional de bacterias endófitas con respecto a tejido vegetal (Figura 2), muestra diferencias significativas, indicando mayores densidades poblacionales en raíces $\left(1.0 \times 10^{11} \mathrm{UFC} / \mathrm{g}\right.$ de tejido) y menores para tallo y hoja respectivamente $\left(1.82 \times 10^{10}\right.$ y $1.15 \times 10^{10}$ UFC/ g de tejido).

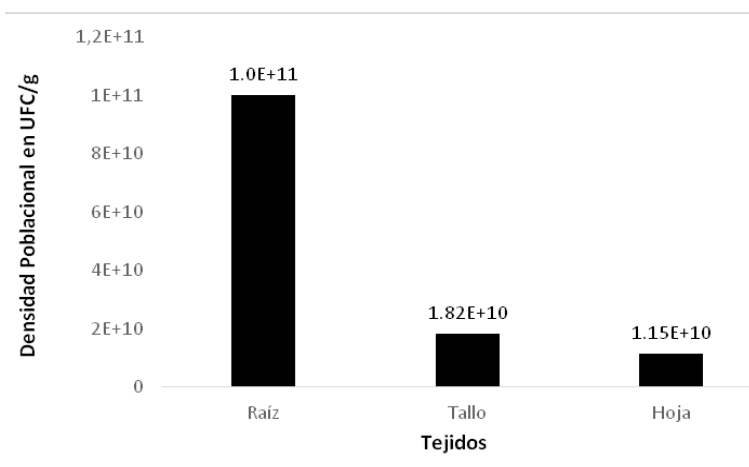

Figura 2. Prueba múltiple de rango para densidad poblacional de bacterias endófitas en función a tejidos de pasto colosoana (Bothriochloa pertusa) ubicado en los corregimientos del municipio de Corozal, Colombia. 2016.

Actividad fijadora de nitrógeno. De 51 morfotipos aislados de bacterias endófitas, 41 presentaron actividad positiva para la fijación biológica de nitrógeno in vitro (figura 3). La mayor presencia de morfotipos se observó en las raíces con un total de 17, para tallo 12 morfotipos, todas presentaron esta propiedad y para hojas 12 fueron positivas. En la figura 4 se observa que el corregimiento con mayor presencia de bacterias endófitas fijadoras de nitrógeno es las peñas donde se presenta con mayor actividad en los diferentes tejidos en comparación con los demás corregimientos.

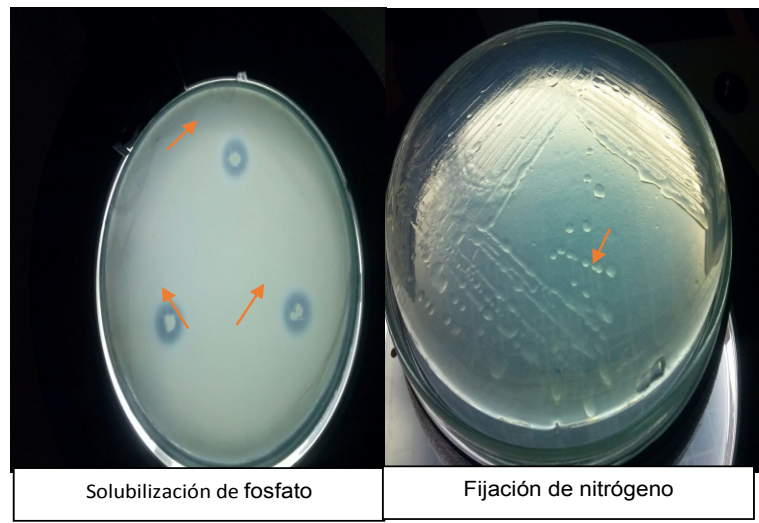

Figura 3. Actividad solubilizadora de fosfato y fijación biológica de nitrógeno in vitro de bacterias endófitas aisladas de pasto colosoana (Bothriochloa pertusa) pertenecientes a fincas ganaderas de los corregimientos del municipio de Corozal- Sucre- Colombia. Año 2016. 


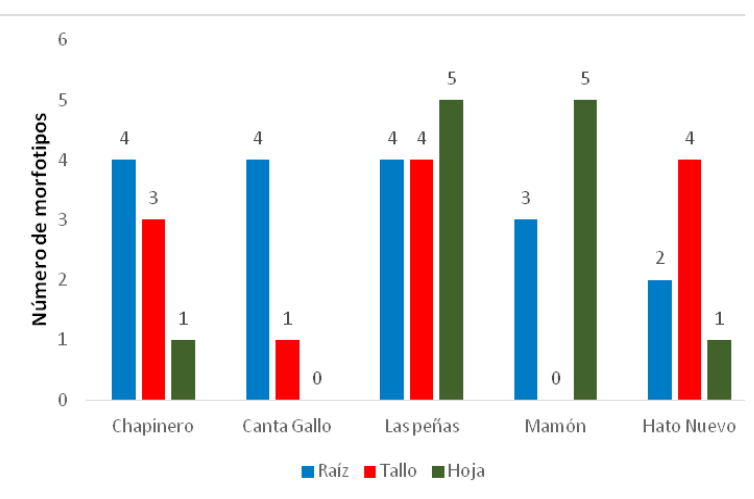

Figura 4. Bacterias endófitas con actividad fijadora de nitrógeno de acuerdo al tejido en los diferentes corregimientos del municipio de Corozal- SucreColombia. Año 2016.

Actividad solubilizadora de fosfato. Los resultados de la actividad in vitro de solubilización de fosfato, mostró que 6 morfotipos presentaron esta actividad. El fósforo aunque es uno de los principales macronutriente esencial para cualquier organismo vivo, se encuentra poco disponible en especial para las plantas, debido a que la mayor parte del fosforo se encuentra en el suelo en forma mineral, lo cual lo hace insoluble y no disponible; solo las formas solubles de este, lo convierten en disponibles tanto para plantas como para microorganismos (BEHERA et al., 2014). Una de las características de las bacterias endófitas es la habilidad de incrementar la movilización del fosfato, por el desarrollo de mecanismos que permiten captar las formas de fosfato insoluble, liberarlo y haciéndolo disponible para la planta (RYAN et al., 2008). Uno de los mecanismos que usan las bacterias para solubilizar fosfato es a través de ácidos orgánicos. La gran mayoría de los ácidos producidos por estas bacterias ya ha sido previamente identificados, entre ellos encontramos los ácidos málico, oxálico, citrato, gluconatos entre otros, los cuales forman complejos con fosfatos de aluminio, hierro o en este caso calcio, presentándose un aumento en cationes $\left(\mathrm{H}^{+}\right)$lo cual reduce el $\mathrm{pH}$ dándose, la liberación de fosfato disponible o soluble (JONES y OBURGER, 2011).

Identificación de bacterias endófitas. De acuerdo al sistema de identificación API 20E se identificaron 2 especies y/o grupo de bacterias aisladas siguiendo la metodología descrita, y presentaron actividad positiva para fijación biológica de nitrógeno y solubilización de fosfatos. Se confirmó la identificación de Pseudomona aeruginosa y Stenotrophomonas maltophilia con las actividades de promoción de crecimiento.

Entre los resultados obtenidos se identificó la bacteria Pseudomona aeruginosa, de acuerdo a la literatura esta bacteria pertenece a la familia Pseudomonadaceae y es un bacilo gramnegativo aerobio, es un microorganismo común en el medio ambiente y puede encontrarse en las heces, el suelo, el agua y las aguas residuales. Puede proliferar en ambientes acuáticos, así como en la superficie de materias orgánicas propicias en contacto con el agua (DE VICTORICA y GALVAN, 2001).

Según el análisis realizado, se identificó Pseudomona aeruginosa como bacteria endófita aislada de pasto colosoana. La prueba in vitro de fijación biológica de nitrógeno, mostró que esta bacteria además de fijarlo biológicamente tuvo la capacidad de solubilizar fosfato y se encontró que esta actividad fue observada en morfotipos aislados de raíces. En estudios realizados por ZHANG et al., (2002), encontró bacterias del genero Pseudomona abundantes en las superficies de las raíces ya que son versátiles en su metabolismo. Entre sus mecanismos de acción se encuentran el aumento de la toma de agua y nutrientes por la planta, la solubilización de fosfatos y la producción de reguladores del crecimiento vegetal. MULETA et al., (2013), identificó géneros de Pseudomonas sp en dos periodos climáticos, sequía y lluvia y determino la presencia de Pseudomona sp con la capacidad de solubilizar fosfatos en plantas jóvenes de guayaba agria (Psidium araca Swartz) y plantas de café que crecían en bosques naturales.

LOREDO et al., (2004), reportó bacterias del genero Pseudomonas, Bacillus y Klebsiella como bacterias promotora de crecimiento vegetal en gramíneas. Las Pseudomonas también son ejemplo de la resistencia que puede llegar a adquirir la planta, pues su participación en asociación con esta aumenta no solo la velocidad sino los niveles de síntesis de fitoalexinas, este grupo de compuestos heterogéneo de bajo peso molecular, pueden ser inducidos a la planta ya sea por moléculas bióticas o abióticas, algunas de 
estas moléculas corresponden a las glicoproteínas y lípidos que se encuentran en la pared celular de algunos microorganismos como bacterias $u$ hongos que pueden liberar la acción de un inductor como el caso de las endopoligalacturonasa que a su vez da lugar a la activación de otro inductor que está presente en la pared celular de la planta (ANAYA, 2003).

Los biofertilizantes de origen microbiano obtenidos a través de los géneros Azotobacter $\mathrm{sp}$, Azospirillum sp, y Pseudomonas sp, han demostrado incrementos en los rendimientos de los cultivos, ahorro de fertilizantes minerales y la disminución de la contaminación ambiental (MANTILLA y ZUMAQUE, 2008). Por ejemplo en un estudio realizado en plantaciones de trigo empleando biofertilizantes comerciales con Azospirillum brasilence (Az1 y Az2) y Pseudomonas fluorecens (Pf), se encontró que los rendimientos del grano incrementaron en 17, 14 y $19 \%$ con los tratamientos Az1, Az2 y Pf respectivamente, en comparación con los testigos sin inoculación ni fertilización (NAIMAN et al., 2009). Para el caso de bacterias promotoras de crecimiento vegetal (BPCV) en pasturas CÁRDENAS et al., (2010) menciona que la inoculación de estas bacterias favorece el crecimiento y nutrición vegetal, en su estudio sugiere que el efecto positivo por parte de las BPCV se puede atribuir a que las bacterias propician el desarrollo vegetal al permitir el incremento en la proliferación de vellosidades de la raíz con lo que incrementa la absorción de agua y nutrientes, así mismo en el estudio realizado por CRIOLLO et al., (2012), Pseudomonas sp y Strenotrophomonas sp tuvieron la capacidad de promover el crecimiento vegetal en Pennisetum clandestinum, incrementando el peso seco y fresco de la planta en relación con el control químico, bajo condiciones de invernadero. Por otra parte DÍAZ et al., (2001), demostraron que Pseudomona aeruginosa cepa 5 ps presentaba efectos promotores de crecimiento vegetal, tanto en la germinación, como en el desarrollo vegetativo del cultivo de lechuga.

Otra de las bacterias identificadas en este estudio es Strenotrophomonas maltophilia, perteneciente al grupo de las Gammaproteobacterias, es una bacteria Gram negativa no fermentadora de glucosa, puede encontrarse en diversas fuentes ambientales, como aguas sucias o residuales, leche cruda, etc. (APISARNTHANARAK, 2003). Con respecto a Stenotrophomonas sp., algunas especies han sido identificadas como patógenas humanas. Sin embargo, ésta especie ha sido aislada de plantas sanas y descrita como una bacteria promotora de crecimiento de varios cultivos de importancia agronómica (IDRIS et al., 2009). La prueba in vitro realizada muestra que esta bacteria tiene la capacidad de fijar biológicamente el nitrógeno y solubilizar fosfatos. Diversos reportes evidencian la variabilidad de las capacidades de promoción de Stenotrophomonas sp. y Pseudomonas sp., como lo mencionan TAULÉ et al., (2011), quienes obtuvieron nueve cepas de Stenotrophomonas sp. a partir de Saccharum officinarum, con producciones de hormonas indólicas entre $6.9-31.8 \mu \mathrm{g} \mathrm{mL}-1$ y sólo una cepa (UYSO27) presentó fijación de nitrógeno mediante actividad de reducción de acetileno. Las rizobacterias promotoras de crecimiento vegetal (PGPR), incluyendo las especies de Pseudomonas sp. y Strenotrophomona sp. identificadas en este estudio, se han reportado ampliamente por su efecto benéfico en diversas plantas incluyendo gramíneas (CÁRDENAS et al., 2010). Otro estudio realizado por MORENO y GALVIS, (2013), determinaron nueve aislados de Stenotrophomonas maltophilia, donde la emergencia de las plantas, el diámetro del tallo y la longitud de las hojas y los tallos fueron las características más importantes que aportaron estas cepas bacterianas gracias a su actividad de fijación de nitrógeno y solubilización de fosfato.

\section{Conclusiones}

Los resultados obtenidos en el presente estudio muestra que las mayores densidades poblacionales de bacterias endófitas se encontraron en el corregimiento de las Peñas del municipio de Corozal-Sucre. Un total de 51 bacterias endófitas se aislaron de pasto colosoana, de las cuales 41 bacterias mostraron actividad en la promoción del crecimiento vegetal mediante las pruebas de fijación de nitrógeno y solubilización de fosfatos. Las bacterias identificadas como Pseudomona aeuroginosa y Stenotrophomonas maltophilia presentaron actividades promotoras de crecimiento, esto indica que estas dos especies de bacterias podrían ser utilizadas como una alternativa biológica de fertilización a base de nitrógeno y fosforo en pastos, el cual permitiría 
aumentar contenido nutricional y así brindar una mejor proteína al sector ganadero. Es importante tener en cuenta que se deben realizar estudios moleculares de verificar su identificación y compararlas con las bases de datos que existen a nivel mundial. También se debe tener en cuenta para futuros experimentos realizar pruebas en campo y así evidenciar la actividad de estas bacterias y por ende mostrar una alternativa biológica que supla los fertilizantes químicos que tanto dañan el medio ambiente.

Agradecimientos. Los autores agradecen a la Universidad de Sucre por toda su colaboración en la ejecución de la investigación.

\section{REFERENCIAS}

AFZAL, M.; KHAN, Q. M.; SESSITSCH, A. 2014. Endophytic bacteria: Prospects and applications for the phytoremediation of organic pollutants. Chemosphere. 117: 232-242.

ALIKHANI, H.; SALEH, N.; ANTOUN, H. 2007. Phosphate solubilization activity of rhizobia native to Iranian soils. Paper presented at the First International Meeting on Microbial Phosphate Solubilization.

ANAYA, A.L. 2003. Ecología química. México D.F: Plaza y Valdés.

APISARNTHANARAK, A.; MAYFIELD, J.L.; GARISON, T. 2003. Risk factors for Stenotrophomonas maltophilia bacteremia in oncology patients: a case-control study. Infect Control Hosp Epidemiol. 24:269274.

BEHERA, B.; SINGDEVSACHAN, S.; MISHRA, R.; DUTTA, S.; THATOI, H. 2014. Diversity, mechanism and biotechnology of phosphate solubilising microorganism in mangrove-a review. Biocatalysis and Agricultural Biotechnology. 3(2): 97-110

BENEDUZI, A.; MOREIRA, F.: COSTA, P. B.; VARGAS, L. K.; LISBOA, B. B.; FAVRETO, R.; PASSAGLIA, L. M. P. 2013. Diversity and plant growth promoting evaluation abilities of bacteria isolated from sugarcane cultivated in the South of Brazil. Applied Soil Ecology. 63: 94-104.

CAJAS, Y.S.; RONDÓN, M.; RAMÍREZ, J.; AMÉZQUITA, E.; RIVERA, M. 2003. Silvopastoral systems to improve cattle productivity and reduce greenhouse gas emissions. Annual report project PE6. Palmira, Colombia: CIAT. 33-40.

CARDENAS, D.; GARRIDO, M.; BONILLA, R.; BALDANI, V. 2010. Aislamiento e identificacion de cepas de Azospirillum sp en pasto guinea (Panicum máximum Jacq.) del Valle del Cesar. Pastos y Forrajes. 33(3): 130- 144.

CRIOLLO, P.J.; OBANDO, M.; SANCHEZ, L.; BONILLA, R. 2012. Efecto de bacterias promotoras de crecimiento vegetal (PGPR) asociadas a Pennisetum clandestinum en el altiplano Cundiboyacense. Revista Corpoica, Ciencia y Tecnología Agropecuaria. 13(2): 189-195.

DAWWAM, G.; ELBELTAGY, A.; EMARA, H.; ABBAS, I.; HASSAN, M. 2013. Beneficial effect of plant growth promoting bacteria isolated from the roots of potato plant. Annals of Agricultural Sciences. 58(2): 195-201.

DE VICTORICA, J.; GALVÁN. M, 2001: Pseudomonas aeruginosa as an indicator of health risk in water for human consumption. Water Science and Technology, 43:49-52. 
DÍAZ, V.R.; FERRERA, J.J.; ALMARAZ, Y.G.; ALCÁNTAR, G. 2001. Inoculación de bacterias promotoras de crecimiento en lechuga. Revista Terra. 19: 327-335

DUTTA, D.; GACHHUI, R. 2006. Novel nitrogen-fixing Acetobacter nitrogenifigens sp. nov., isolated from Kombucha tea. International Journal of Systematic and Evolutionary Microbiology. 56(8): 1899-1903.

HARDOIM, P. R.; VAN OVERBEEK, L. S.; ELSAS, J. D. 2008. Properties of bacterial endophytes and their proposed role in plant growth. Trends in microbiology. 16(10): 463-471.

HERNÁNDEZ, M. I.; CHAILLOUX, M. 2001. La nutrición mineral y la biofertilización en el cultivo del tomate (Lycopersicon esculentum Mill). Temas de Ciencia y Tecnología. 15(3): 11-27.

HU, Y.; RIBBE, M. W. 2013. Nitrogenase assembly. Biochimica et Biophysica Acta (BBA) - Bioenergetics. 1827(8-9): 1112-1122.

IDRIS, A.; LABUSCHAGNE, N.; KORSTEN L. 2009. Efficacy of rhizobacteria for growth promotion in sorghum under greenhouse conditions and selected modes of action studies. Journal of Agricultural Science. 147:17-30.

JONES, D. L.; OBURGER, E. 2011. Solubilization of phosphorus by soil microorganisms Phosphorus in Action (pp. 169-198): Springer.

LASCANO, C.E.; ARGEL, P.J. 2011. Descripción y atributos de especies y cultivares de Bothriochloa. Seminario Taller sobre B. pertusa. Comité de Ganaderos de Ibagué.

LOREDO, C.; LÓPEZ, L.; ESPINOSA, V. 2004. Bacterias promotoras del crecimiento vegetal asociadas con gramíneas. Terra Latinoamericana, 22(2): 225-239.

MANTILLA, C.L.; ZUMAQUE, L.E. 2008. Bacterias Diazotróficas con Potencial Biofertilizante para una Agricultura Limpia y Productiva. Monteria, Cordoba: (Sic) Editorial Ltda.

MARON, P.A.; RANJARD, L.; MOUGEL, C.; LEMANCEAU, P. 2007. Metaproteomics: a new approach for studying functional microbial ecology. Microbial ecology. 53(3): 486-493.

MORENO, Y.F.; GALVIS, A. 2013. Potencial biofertilizante de bacterias diazótrofas aisladas de muestras de suelo rizosférico. Revista Pastos y Forrajes. 36 (1): 33-37.

MULETA, D.; ASSEFA, F.; BÖRJESSON, E.; GRANHALL, U. 2013. Phosphatesolubilising bacteria associated with Coffea arabica L. in natural coffee forests of southwestern Ethiopia. Journal of the Saudi Society of Agricultural Sciences.12(1):73-84.

NAIMAN, A.; LATRONICO, A.; GARCIA, I. 2009. Inoculation of wheat with Azospirillum brasilence and Pseudomonas fluorecens: Impact on the production and culturable rhizosphere microflora. European Journal of Soil Biology. 45(1), 44-51.

PÉREZ, C.; ROJAS, J.; FUENTES, C. 2010. Diversidad de bacterias totales y endófitas asociadas a raíces del pasto Bothriochloa pertusa (L) A. Camus. Revista Colombiana de Ciencia Animal. 2(1): 58-72.

PÉREZ, C.; TUBERQUIA, A.; AMELL, D. 2014. Actividad in vitro de bacterias endófitas fijadoras de nitrógeno y solubilizadoras de fosfatos. Revista Agron. Mesoam. 25(2):213-223. 
PORTELA, V.; BRITO, A.; PIÑEROS, R.; MORA, J.R. 2011. Evaluación agronómica y productiva del pasto Colosoana (Bothriochloa pertusa) expuesto a diferentes tipos de fertilizantes y calidades de suelos en el departamento del Tolima. Proyecto de trabajo de grado. Universidad del Tolima, 30.

RODRIGUEZ, H.; FRAGA, R.; GONZALEZ, T.; BASHAN, Y. 2006. Genetics of phosphate solubilization and its potential applications for improving plant growth-promoting bacteria. Plant and soil. 287(1-2):15-21.

RYAN, R. P.; GERMAINE, K.; FRANKS, A.; RYAN, D. J.; DOWLING, D. N. 2008. Bacterial endophytes: recent developments and applications. FEMS Microbiology Letters. 278(1): 1-9.

ROSENBLUETH, M.; MARTÍNEZ, E. 2006. Bacterial endophytes and their interactions with hosts. Molecular Plant-Microbe Interactions, 19(8): 827-837.

SYLVIA, D. M.; FUHRMANN, J. J.; HARTEL, P.; ZUBERER, D. A. 2005. Principles and applications of soil microbiology: Pearson Prentice Hall New Jersey

SHWETA, S.; BINDU, J. H.; RAGHU, J.; SUMA, H.; MANJUNATHA, B.; KUMARA, P. M.; UMA SHAANKER, R. 2013. Isolation of endophytic bacteria producing the anti-cancer alkaloid camptothecine from Miquelia dentata Bedd.(Icacinaceae). Phytomedicine. 20(10): 913-917.

TAULÉ, C.; MAREQUE, C.; BARLOCCO, F.; HACKEMBRUCH, V. M.; REIS, M.; BATTISTONI, F. 2012. The contribution of nitrogen fixation to sugarcane (Saccharum officinarum L.), and the identification and characterization of part of the associated diazotrophic bacterial community. Plant and Soil. 356:35-49. TROPICAL FORAGES, 2013. Bothriochloa pertusa. http://www.tropicalforages.info/key/Forages/Media/ Html/Bothriochloa_pertusa.htm

VERA, 2004. Perfiles por país del recurso forraje/pasto. FAO. http:// www.fao.org/ag/AGP/AGPC/doc/ Counprof/PDF\%20files/Colombia-Spanish.pdf

WARD, D. M. 2006. A macrobiological perspective on microbial species. Microbe-american society for microbiology. 1(6): 269-278.

YANG, P.; SUN, Z.X.; LIU, S.Y.; LU, H. X.; ZHOU, Y.; SUN, M. 2013. Combining antagonistic endophytic bacteria in different growth stages of cotton for control of Verticillium wilt. Crop Protection. 47, 17-23.

ZHANG , S.; MOYNE, A.L.; REDDY, M.S.; KLOEPPER, J.W. 2002. The role of salicylic acid in induced systemic resistance elicited by plant growth-promoting rhizobacteria against blue mold of tobacco. Biological Control. 25: 288-296. 